\title{
DERECHO DE LAS MINORÍAS Y TOLERANCIA*
}

RODOLFO VÁZQUEZ

DEPARTAMENTO ACADÉMICO DE DERECHO INSTITUTO TECNOLÓGICO AUTÓNOMO DE MÉXICO

El 16 de diciembre de 1984, mediante asamblea convocada por el señor Florentino Díaz Rangel, presidente municipal de Santa María de Taxicaringa, se acordó ahorcar y quemar con leña verde a Alejandro Barraza Sosa y Matilde Díaz Rangel, quienes se dedicaban a la práctica de la brujería. La decisión buscaba liberar a la comunidad tepehuana de los brujos, designados como perniciosos por los habitantes. El 19 de diciembre, se ejecutó la sentencia en los términos acordados, con la participación de una decena de los miembros de la comunidad. Los hechos fueron denunciados en la capital del estado de Durango y fueron detenidos los involucrados quienes narraron los hechos sustentándose en la decisión de sus autoridades tradicionales. ${ }^{1}$.

El 25 de septiembre de 1992, el Desarrollo Integral de la Familia (DIF) municipal, turnó al agente del Ministerio Público el caso de una niña huichola de 10 años que declaró haber sido violada por su padrastro. La madre, de 34 años, aseguró que actualmente tiene otro marido con quien procreó cuatro hijos. Ella niega que su marido violara a su hija, pero en caso de ser cierto lo perdona porque, entre "nosotros los huicholes así se acostumbra ya que los papás pueden vivir con sus hijos. Además si meten a la cárcel a mi marido después quién va a mantener a mis hijos". Por su parte, el denunciado, de 27 años de edad, declara: "Que sí es cierto tal y como dice el acta de la Policía Judicial [992], ya que no recuerdo si fue en año nuevo o el diez de mayo cuando hubo fiesta, llegué en compañía de mi mujer a la casa y abracé a la niña y le bajé los calzones y le hice el amor [... ] y después que hicimos el amor, se metió a la casa llorando y mi mujer estaba dormida y mi mujer es su mamá; al día siguiente yo le dije lo que pasó, pero también

* Una versión anterior de este trabajo apareció publicada, bajo el título "Derechos y tolerancia", en León Olivé y Luis Villoro (comps.), Filosofía moral, educación e historia. Homenaje a Fernando Salmerón, UNAM, 1996.

1 Véase Watler Beller Taboada, et al., Las costumbres jurídicas de los indígenas en México, Comisión Nacional de Derechos Humanos, México, 1994, p. 90. 
le dije que cuando la niña estuviera grande me iba a casar con ella para que fuera mi mujer, y ella me dijo que estaba bien ya que así se acostumbra entre nosotros [...] Pero vuelvo a decir que es nuestra costumbre ya que podemos tener una, dos o tres mujeres."

En una comunidad indígena de Oaxaca, un hombre mató a su amigo en una reyerta, ambos en estado de embriaguez. Después de varios días de discusión, el consejo de ancianos de la comunidad, como autoridad tradicional decidió que el culpable, siendo soltero, debía casarse con la viuda de su víctima y sostener a los hijos de éste. De esta manera se resolvió el problema del sostén económico de la familia de la víctima, el culpable asumió su culpa y su responsabilidad, se evitaron conflictos potenciales entre las familias de ambos y se mantuvo el equilibrio social de la comunidad, [...] Sin embargo, enterada del homicidio cometido, la autoridad judicial del Estado quiso aprehender al asesino. La comunidad se negó a entregarlo y la autoridad gubernamental llamó al ejército para proceder en su contra. Ante la posibilidad de un conflicto violento con la comunidad, el gobernador del Estado decidió respetar la decisión de la comunidad, aun contraviniendo la legislación penal del propio Estado. ${ }^{3}$

En estos tres casos el común denominador es que se trata de grupos minoritarios que hacen valer sus costumbres y tradiciones como justificación de los actos realizados. Asimismo, tales costumbres y tradiciones, no reconocidas aún como derecho por el orden jurídico local ni nacional, colisionan con los valores éticos y jurídicos de Estados nacionales constitucionalmente democráticos. Por supuesto, esta colisión de valores o de derechos, como se prefiera, debe ser resuelta.

El debate contemporáneo, en torno a lo que se conoce hoy día como el problema del multiculturalismo, oscila entre dos extremos éticamente injustificables: o la integración indiscriminada o la tolerancia incondicional de los grupos minoritarios. Luis Villoro ha puesto de manifiesto esta antinomia, referida al caso de México y muy especialmente en el contexto del levantamiento zapatista en Chiapas, en los siguientes términos:

En el caso de México, el primer extremo sería el reconocimiento de soberanía política a las comunidades indígenas, lo que supondría la disolución del Estado nacional; el segundo, la integración forzada de las culturas minoritarias a la cultura nacional hegemónica. Ambas posiciones tienden al mismo resultado: la destrucción de las culturas minoritarias; la primera, por dejarlas aisladas y sin defensa; la segunda, por desintegrarlas.

2 Ibid., p. 92.

3 Véase Rodolfo Stavenhagen, Derecho indígena y derechos humanos en América Latina, El Colegio de México-lnstituto Interamericano de Derechos Humanos, México, 1988, p. 310. 
La solución de la antinomia no puede estar en ninguno de los dos extremos. La aceptación de la multiplicidad de los pueblos, sin un núcleo de unidad, implica la destrucción del Estado, la imposición de la unidad sin respeto a la diversidad, conduce a un Estado opresivo. La solución sólo puede darse en una forma de síntesis entre unidad y multiplicidad. Entre la ruptura de la asociación política existente y su mantenimiento por coacción, cabe una tercera vía: la transformación de la asociación política, de ser obra de la imposición de una de las partes a ser resultado de un consenso entre sujetos autónomos. ${ }^{4}$

En efecto, el debate no debe plantearse en términos de "limpieza étnica" o "guetización" aunque por desgracia no falten ejemplos históricos cercanos o contemporáneos de uno y de otro. Las propuestas deben ubicarse, más bien, en esa zona intermedia que supone el reconocimiento fáctico de las minorías y la posibilidad de un consenso entre las partes. Planteado en términos de derechos humanos, no se trata de sostener una incompatibilidad absoluta entre los derechos liberales y los derechos culturales sino en lo que Paolo Comanducci ha llamado una incompatibilidad relativa entre ambos. Según ésta existen criterios para resolver las antinomias sin que sea necesario rechazar el reconocimiento de alguno de ellos. Estas posiciones proponen algún tipo de jerarquización entre los diferentes tipos de derechos, que se pueden agrupar en dos grandes tendencias: la que construye una jerarquía en orden descendente que va de los derechos liberales a los culturales y la tendencia contraria que construye la jerarquía en orden ascendente. ${ }^{5}$ En otros términos, o la supremacía de los derechos liberales sobre los culturales o la supremacía de estos últimos sobre los primeros.

En las páginas que siguen me propongo: I. revisar críticamente algunas propuestas teóricas que confieren prioridad ética a la comunidad cultural sobre el individuo; y II. justificar mi preferencia por una concepción liberal de la persona moral y ofrecer un par de argumentos en favor de la primacía de los derechos liberales sobre los culturales. Concluiré que una sociedad multicultural es posible sobre la base del establecimiento incondicional de los derechos derivados del principio de autonomía personal y que la pretensión de imparcialidad y universalidad de tales derechos es el mejor criterio del que disponemos para una sana convivencia entre las culturas.

Desde mediados de los setenta y a lo largo de los ochenta hasta nuestros días, se ha ido desarrollando el llamado comunitarismo que, en buena medida,

4 Luis Villoro, "Sobre derechos humanos y derechos de los pueblos", Isonomía, Revista de Teoría y Filosofía del Derecho, no. 3, rTaM-Fontamara, México, octubre 1995, p. 9.

5 Véase Paolo Comanducci, "Derechos humanos y minorías: un acercamiento analítico neoilustrado", en ibid., p. 29. 
centra sus críticas en el liberalismo y, de manera especial, en el liberalismo igualitario de autores como John Rawls, el Rawls de Una teoría de la justicia. Filósofos como Charles Taylor, Michael Sandel, Alasdair Macintyre y Michael Walzer, que forman el cuerpo compacto del comunitarismo, coinciden en denunciar la concepción ahistórica y desencarnada del individuo dotado de derechos concebidos como anteriores a su entorno social y político. Un liberalismo así concebido es acusado de ser el responsable de la destrucción de los valores comunitarios - solidaridad, patriotismo, fraternidad y, en general, virtudes cívicas-y, por consiguiente, de favorecer un debilitamiento de la vida pública. El cambio operado a partir de esta concepción liberal ha sido, en palabras de Sandel:

de una filosofía pública de propósitos comunes a una de procesos imparciales, de una política de lo bueno a una política de lo correcto, de una república nacional a una república procedimental. ${ }^{6}$

Es verdad que esta crítica comunitarista -de la que no deseo ocuparme expresamente en estos momentos- ha encontrado respuesta entre los liberales comenzando por el mismo Dworkin pero, como afirma Nino, las defensas de la posición kantiana han sido sorprendentemente débiles y en algunos casos hasta han constitutido una franca retirada. ${ }^{7}$ Esta retirada liberal ha comenzado por el mismo Rawls y se puede apreciar, igualmente, en otro paladín del liberalismo como Thomas Nagel.

En su ensayo "El derecho de los pueblos", John Rawls se apoya en su idea del "consenso sobrepuesto" (overlapping consensus) para defender la compatibilidad de una sociedad no liberal con una liberal si se aceptan los siguientes requerimientos: 1 . que sea pacífica y no expansionista; 2 . que su sistema de legalidad satisfaga ciertos requisitos de legitimidad a los ojos de su propia gente; y 3. que, como consecuencia de lo anterior, se respeten los derechos humanos básicos. Para Rawls una sociedad que satisface estos requisitos es una "sociedad jerárquica bien ordenada" (well-ordered hierarquical society). En estas sociedades, piensa Rawls:

los individuos no ejercen el derecho a la libre expresión como en una sociedad liberal; pero como miembros de asociaciones y cuerpos corporativos tienen el derecho, en algún punto del proceso de consulta a expresar su disenso político

6 Michael Sandel, "The Procedural Republic and the Unencumbered Self", en Shlomo Avineri y Avner de Shalit, Communitarianism and Individualism, Oxford University Press, 1992, pp. 26-27.

7 Véase Carlos S. Nino, Ética y derechos humanos, 2a. ed. ampliada y revisada, Astrea, Buenos Aires, 1989, pp. 142 s. 
y el gobierno tiene la obligación de tomar seriamente en cuenta tal disenso y ofrecer una respuesta reflexiva. ${ }^{8}$

Me resulta difícil aceptar la compatibilidad entre ambas sociedades, como pretende Rawls, si, por un lado, se parte de una relativización de los principios de justicia y de una confusión entre legitimación y legitimidad ${ }^{9}$ y, por el otro, se debilita el principio de autonomía personal limitando la libertad de expresión y abriendo las puertas a esquemas francamente corporativistas.

Por su parte, en su libro Igualdad y parcialidad, Nagel parte de la idea de que en nuestra vida existe una tensión constante entre el punto de vista objetivo, la perspectiva desde ninguna parte, que es la de la imparcialidad y el altruismo, y el punto de vista subjetivo que toma en cuenta las circunstancias particulares del individuo. Nagel se muestra escéptico ante la posibilidad de concebir una moral que incluya tanto razones agencialmente neutrales (agent-neutral reasons) como razones agencialmente relativas (agent-relative reasons) con el fin de superar la tensión o el conflicto. Contra la posibilidad del altruismo, Nagel sostiene ahora que:

El mero altruismo [...] no provee un punto de vista común desde el cual cada uno pudiera alcanzar las mismas conclusiones -y ésta es la esencia de la idea contractualista o kantiana de legitimidad. El altruismo por sí mismo genera tantos puntos de vista conflictivos como concepciones del bien existen. ${ }^{10}$

El punto de vista personal ya no lo integra Nagel en la perspectiva de la imparcialidad porque ésta misma no es universalizable ni objetiva y tiene poca relevancia moral si se la considera sólo desde un ángulo procedimental.

Creo, que el error de Nagel, como el de buena parte de los comunitaristas, es considerar la autonomía y la dignidad de la persona, implícitas en la idea de imparcialidad que exige el discurso moral, como un plan de vida más _-el que proponen las sociedades liberales democráticas-entre otros planes de vida posibles y no como los principios subyacentes y necesarios para la

8 John Rawls, "The Law of Peoples", en Stephen Shute y Susan Hurley (comps.), On Human Rights, Basic Books, Nueva York, 1993, p. 62.

9 Para la distinción entre ambos conceptos véase Ernesto Garzón Valdés, El concepto de estabilidad de los sistemas polf́ticos, Fontamara, México, 1992 (Biblioteca de Ética, Filosofía del Derecho y Política, no. 21), pp. 15 s. Garzón Valdés distingue claramente entre legitimidad como justificación moral de un sistema político y legitimación que es la aceptación generalizada del sistema y de sus normas de acuerdo con lo que $H$. Hart denomina "el punto de vista interno frente a las normas". Rawls termina reduciendo el problema de legitimidad a un problema de legitimación.

10 Thomas Nagel, Equality and Partiality, Oxford University Press, 1991, p. 164. 
materialización de cualquier plan de vida posible. Lo que el liberalismo kantiano defiende no es una concepción descriptivista de la persona moral sino normativista, es decir, una concepción no preocupada por la pregunta ¿cómo son los individuos en sí mismos y en sus relaciones comunitarias?, sino por la pregunta ¿cómo deben ser tratados los individuos? Reprochar a los liberales que han olvidado al sujeto concreto es apuntar las críticas hacia un blanco inexistente.

Entre nosotros, y desde una crítica fina a Ernesto Garzón Valdés en torno a su concepción de homogeneidad social, Luis Villoro toma como punto de partida la propuesta liberal de que en toda asociación política voluntaria se deben aceptar las condiciones que la hacen posible, a saber:

1. el respeto a la vida del otro, por lo tanto. La satisfacción de las necesidades naturales necesarias al mantenimiento de esa vida; 2 . la aceptación de su autonomía, en el doble sentido de aceptación de su capacidad de elección conforme a sus propios valores y de su facultad de ejercer esa elección; 3. la aceptación de una igualdad de condiciones en el diálogo que conduzca al convenio, lo cual incluye el reconocimiento por cada quien de la posibilidad de que los otros guíen sus decisiones por los fines y valores que le son propios: 4. por último, para que se den esas circunstancias, es necesaria la ausencia de coacción entre las partes.

Parece que estas condiciones ideales del discurso no presentan problemas siempre que los sujetos pertenezcan a la misma comunidad de cultura. El problema surge cuando no se comparten las mismas creencias básicas sobre fines y valores. Entonces cabria preguntarse si entre tales condiciones no habría que incluir el respeto al contexto cultural precisamente para garantizar a las diferentes comunidades culturales la autonomía que haga posible la elección de los individuos. La respuesta de Villoro es afirmativa:

Los derechos básicos comprenden el derecho a la autonomía de la persona. Pero la persona no es un individuo sin atributos, incluye la conciencia de su propia identidad como miembro de una colectividad y ésta no puede darse más que en contexto cultural [...] Las creencias básicas, que determinan las razones válidas, los fines elegibles y los valores realizables, varían de una cultura a otra. Por lo tanto, el respeto a la autonomía de las personas incluye el de las comunidades culturales a las que pertenecen. El "derecho de los pueblos" sólo puede contarse entre los derechos humanos fundamentales, en la medida en que el "pueblo" sea una condición para la autonomía de la persona... "11

El problema que veo en la propuesta de Villoro es, precisamente, el de la prioridad ética que otorga, a fin de cuentas, al contexto cultural sobre

11 Luis Villoro, op. cit., pp. $10 \mathrm{~s}$. 
el principio de autonomía kantiano. Si el contexto cultural de elección es un bien primario y se incluye entre aquellos que conforman lo que Garzón Valdés ha llamado el "coto vedado", 12 merecería por ese sólo hecho el mismo respeto que el bien primario de la libertad individual pero, entonces, ¿qué sucedería si aquél entra en contradicción con esta última? El respeto al contexto cultural de elección exigiría, por ejemplo, la violación de la niña huichola, la quema de los brujos tepehuanes, o sencillamente, el incumplimiento del principio de igualdad en la aplicación de la justicia penal para el caso del homicida oaxaqueño. Claro que Villoro no aceptaría estas consecuencias pero si la respuesta es que no se deben permitir estas acciones porque violan los derechos liberales entonces debemos aceptar la supremacía de estos últimos sobre los derechos culturales y fijar límites muy claros a la tolerancia. ${ }^{13}$

Pienso que la filosofía que mejor responde a la supremacía de los derechos liberales sobre los culturales es la que, a partir del primer Rawls, se conoce como liberalismo igualitario. Esta filosofía toma distancia no sólo frente a posiciones tradicionalistas y comunitaristas, sino también dentro de las mismas filas liberales, frente a posiciones utilitaristas y libertarias. En efecto, con respecto a estas últimas que también reconocen el principio de autonomía personal, el liberalismo igualitario se presenta como una tercera alternativa que, por un lado, rechaza el liberalismo holista de los

12 Véase Emesto Garzón Valdés, "Representación y democracia", en Derecho, ética y política, Centro de Estudios Constitucionales, Madrid, 1993, pp. $641 \mathrm{~s}$.

13 En un ensayo reciente Villoro suaviza su posición comunitaria para proponer ahora un modelo igualitario que lejos de tener conflictos con el modelo liberal "pretende llevarlo a su término". En la misma línea de argumentación de Raz ("Multiculturalism: A Liberal Perspective", en Ethics in the Public Domain, Oxford, 1994), Villoro piensa que el ideal de autonomía liberal sólo es realizable en una sociedad multicultural donde la presencia de diferentes culturas constituye un valor por sí mismo y donde: "El respeto a la autodeterminación de todos los miembros de la sociedad no es sólo condición de una asociación justa, sino el ideal regulativo de la acción política." De esta manera: "Una política igualitaria plantearía el valor superior de la pluralidad en la unidad [...] Única e irremplazable es cada cultura, pues no hay una sola que no manifieste una faceta valiosa de la realidad. Y la realidad está constituida por la unidad de esa diversidad" ("Igualdad y diferencia: un dilema político", en León Olivé y Luis Villoro (comps.), Filosofía moral, educación e historia. Homenaje a Fernando Salmerón, UNAM, México, 1996). Difícilmente se podría disentir de la propuesta de Villoro siempre que se acepte: a) que el carácter único e irrepetible de cada cultura no garantiza ipso facto su legitimidad moral, y b) que tomarse en serio el respeto a la autodeterminación de cada uno de los miembros de la sociedad significa reconocer el derecho de asociación voluntaria de cada individuo y la eventual disidencia de éstos con respecto a su comunidad $-\mathrm{y}$ los valores que la integransin represiones subsecuentes. La condición b) sería la justificación moral de a), que vendría a suponer la prioridad de los valores liberales sobre los comunitarios. 
utilitaristas, orientado al "incremento de la autonomía global de un grupo como si se tratara de un solo individuo" y, por otro, rechaza el liberalismo conservador de los libertarios que pretende "que la autonomía se distribuya espontáneamente" y "dejar intacta la autonomía que cada uno parece (ilusoriamente) haber alcanzado por sí mismo". El liberalismo igualitario pretende, en términos de Carlos Nino:

maximizar la autonomía de cada individuo por separado en la medida en que ello no implique poner en situación de menor autonomía comparativa a otros individuos. ${ }^{14}$

Como se puede apreciar, esta directiva es una reformulación del principio de diferencia de Rawls, que pone el acento en el valor de la autonomía y en la obligación de expandir la de aquéllos cuya capacidad para elegir y materializar planes de vida esté más restringida. Si se parte de este principio para caracterizar el liberalismo, es claro que éste responde satisfactoria y plenamente a las críticas que comúnmente se le hacen sobre la base de valores igualitarios.

La crítica al liberalismo de que atenta contra la igualdad se ha apoyado en la idea de que frente a la tensión entre los valores de libertad e igualdad, el liberalismo otorga prioridad al primero argumentando que la idea de autonomía individual es antagónica con exigencias de apoyo solidario a los más necesitados.

La respuesta a esta crítica consiste en mostrar que no existe una tensión entre libertad e igualdad si se reconoce que ambos valores responden a estructuras diferentes pero complementarias. La libertad es un valor sustantivo, cuya extensión no depende de cómo está distribuido entre diversos individuos, ni incluye a priori un criterio de distribución. En cambio, la igualdad es en sí misma un valor adjetivo que se refiere a la distribución de algún otro valor. La igualdad no es valiosa si no se predica de alguna situación o propiedad que es en sí misma valiosa. Esto sugiere la posibilidad de combinación de ambos valores: la justicia consiste en una distribución igualitaria de la libertad bajo el criterio de que las diferencias de autonomía pueden estar justificadas si la mayor autonomía de algunos sirve para incrementar la de los menos autónomos y no produce ningún efecto negativo en la de estos últimos.

Esta reformulación del principio de diferencia supone, por supuesto, la necesidad de deberes positivos especiales por parte del Estado para promover la autonomía de los menos autónomos y, también, el reconocimiento de bienes básicos que son compatibles con la autonomía personal en la medida 
en que se identifican como estado de cosas que son prerrequisitos para la materialización de planes de vida libremente elegidos.

Si se acepta el punto de vista anterior, el liberalismo muestra que, lejos de ser un adversario de los derechos sociales y culturales - como los derechos a la salud, a una vivienda digna, a un salario justo, a la educación, al acceso al patrimonio cultural, etc.-- éstos son una extensión natural de los derechos individuales. Asi pues, sería inconsistente reconocer los derechos referidos a la vida $o$ a la integridad física y no admitir que ellos se violan cuando se omite otorgar los medios necesarios para su goce y su ejercicio. El liberalismo se opone, entonces, a quienes sostienen que los derechos negativos son los únicos derechos existentes. Contra esta posición, el liberalismo igualitario otorga la misma relevancia moral a la actividad como a la no actividad, de tal manera que, según su concepción, los derechos se violan no sólo por actos positivos sino también por omisiones.

Este esbozo general del liberalismo igualitario supone una concepción de la persona moral cuyas características se pueden inferir de la misma práctica de la discusión moral presente en toda asociación política voluntaria: 1. las personas morales están constituidas por su capacidad de elegir fines, adoptar intereses y formar deseos; 2. tal capacidad de elegir fines, adoptar intereses y formar deseos es previa - supone un sujeto subyacente- a cualquier fin, interés o deseo; 3 . esta separación de la persona de cualquier fin, interés o deseo permite también aislarla del flujo causal -económico, histórico, político, social-en el que, como cualquier fenómeno empírico, está inmersa; 4. las personas están también separadas entre sí. Esto significa que tienen sistemas separados de fines e intereses y que son centros de elecciones y decisiones; 5 . como consecuencia de todo lo anterior, si algo es una persona moral, nada que esté compuesto por ella o esté constituido a partir de ella puede ser también persona moral; en particular, las personas colectivas no son personas morales. ${ }^{15}$

Sobre la última característica debe insistirse en que, desde una perspectiva liberal, las concepciones que privilegian éticamente a la comunidad por encima del individuo terminan aceptando una forma de integrismo por la cual la existencia y el bienestar del individuo dependen de la existencia y del bienestar de la comunidad a la que pertenece. Ronald Dworkin critica con razón esta forma de integración que llama "metafísica" porque termina sucumbiendo al antropomorfismo. La integración metafísica sugiere que tal integración: 
depende de una metafísica barroca que afirma que las comunidades son entidades fundamentales en el universo y que los seres humanos individuales son sólo abstracciones o ilusiones. ${ }^{16}$

Lo que está implícito en la crítica de Dworkin es la idea de que las entidades colectivas - comunidad, nación, pueblo, estado- no poseen los atributos de individualidad, autonomía y dignidad que caracterizan a la persona moral, y extrapolarlos gratuitamente a las entidades colectivas es, por supuesto, una antropomorfización.

A partir de esta concepción de la persona moral se pueden esbozar al menos dos argumentos en favor de la primacía de los derechos liberales sobre los culturales:

\section{El argumento del individualismo ético}

Según este argumento, y en una síntesis apretada, los individuos valen más que los grupos a los que pertenecen. Más aún, los grupos valen sólo por y en virtud de los individuos que los componen. Y así también para las culturas: valen en cuanto tienen valor los individuos que las comparten, y no tienen ningún valor intrínseco que permita idealizarlas o hasta absolutizarlas como parece desprenderse de la siguiente afirmación de Bonfil Batalla: "La única civilización, las únicas culturas auténticas, son las que encarnan los pueblos indios." ${ }^{17}$ Más allá del romanticismo que inspira esta frase, toda cultura puede y debe ser modificada o abandonada si deja de valer para los individuos. En este sentido tiene razón David Gauthier cuando sostiene que:

La idea de que las formas de vida tienen derecho a sobrevivir [...] es un recién llegado al escenario moral. Es también una idea totalmente equivocada. Son los individuos los que cuentan; las formas de vida importan como expresión y sustento de la individualidad humana. ${ }^{18}$

Por ello la mejor defensa de las minorías culturales es la superación del relativismo cultural y la afirmación del individuo en tanto agente moral. Esto no significa que se deba ignorar la diversidad cultural en aras del valor incondicionado del progreso, a todas luces absurdo. De lo que se trata es de encontrar principios que, respetando la pluralidad, puedan ser compartidos

16 Ronald Dworkin, op. cit., pp. 208-210.

17 Guillerrno Bonfil Batalla, Introducción a la recopilación de documentos Utopla y revolución en el pensamiento político contemporáneo de los indios en América Latina citado por Emesto Garzón Valdés, "El problema ético de las minorías étnicas", en op. cit., p. 537.

18 David Gauthier, Morals by Agreement, Clarendon Press, Oxford, 1986, p. 288. 
por todos los agentes. Ello significa que no serán aceptados aquellos que destruyan la calidad moral de los agentes. ${ }^{19}$

Desde esta perspectiva, los derechos culturales no deben adscribirse a grupos o a la cultura de las minorias "como objeto que se considera holísticamente dotado de un valor intrínseco". Estos derechos deben ceder si entran en contradicción con los derechos liberales como valores que hay que atribuir a cada individuo en cuanto ser único e irrepetible. Por ello coincido con Rodolfo Stavenhagen cuando afirma que:

los derechos grupales o colectivos deberán ser considerados como derechos humanos en la medida en que su reconocimiento y ejercicio promueven a su vez los derechos individuales de sus miembros.

Pero, cuando los derechos de una comunidad entran en colisión con los derechos individuales, entonces:

no deberán ser considerados como derechos humanos aquellos derechos colectivos que violan o disminuyen los derechos individuales de sus miembros [...] Todo el aparato conceptual de los derechos humanos descansa sobre un imperativo moral: el valor intrínseco de la vida, la libertad y la dignidad del ser humano. En el logro de este imperativo tendrán que complementarse tanto los derechos individuales como los colectivos. ${ }^{20}$

Es en esta misma línea de argumentación que Fernando Salmerón ha propuesto recientemente, a partir de una crítica fina a Charles Taylor, una vuelta a Kant.

Para Taylor, en la interpretación de Salmerón, "el carácter liberal de una organización no se funda en su neutralidad frente a los ideales de vida de sus miembros, sino en su manera de conducirse frente a las minorías y, ante todo, en su respeto por los derechos fundamentales de todos ellos". Taylor admite, con todo, que "debe distinguirse entre libertades fundamentales - lo que llamamos derechos humanos- que no debe coartar ninguna autoridad, y las inmunidades y privilegios que pueden ser restringidos por razones de política pública si bien reconoce que aquí se da una diversidad de objetivos cuyo deslinde no es fácil y tiene que ocasionar tensiones y dificultades". Sin embargo, continúa Salmerón:

más allá del posible carácter endémico de los conflictos que acepta Taylor, lo que está en juego en este punto es algo mucho más radical desde la perspectiva de la

19 Véase Emesto Garzón Valdés, op. cit., p. 538.

20 Rodolfo Stavenhagen, "Los derechos indígenas: algunos problemas conceptuales", Isonomía, Revista de Teoría y Filosofía del Derecho, no. 3, ITAM-Fontamara, México, octubre 1995, p. 120. 
ética. Acudir a los derechos fundamentales -que son derechos individualescomo el límite que no puede ser rebasado en nombre de los derechos de los pueblos, es una manera de aceptar aunque sea solamente bajo convicción democrática, el fin negativo señalado por Kant: el principio de la humanidad como fin en sí mismo. Es decir, en el sentido último de autonomía personal: del ser humano como voluntad racional autolegisladora, no necesitada del consenso de la humanidad. ${ }^{21}$

La vuelta a Kant que propone Salmerón significa, entonces, la prioridad del principio de dignidad sobre el principio de identidad; de una política de la igualdad sobre una política de la diferencia. En fin, de los derechos liberales sobre los culturales.

Otro problema distinto y sin duda importante es el modo en el que se debe hacer valer esta primacía de unos derechos sobre otros. Desde el punto de vista jurídico no parecen apropiadas la aplicación inflexible del principio "la ignorancia de la ley no excusa su cumplimiento" ni el alegato de la inimputabilidad, por ejemplo, del indígena, salvo en los casos que efectivamente pueden aducirse. En este punto me parece acertada la opinión del grupo de trabajo coordinado por Walter Beller Taboada cuando recomienda como más adecuado:

recurrir al principio de imposibilidad de conocer la antijuridicidad de la conducta, bajo el supuesto del error de prohibición vencible o invencible. Por error de prohibición se entiende el desconocimiento de que la conducta que se realiza es ilícita. El error vencible podría atenuar la pena; el error invencible podría ser eximente de responsabilidad. ${ }^{22}$

\section{El argumento de la imparcialidad}

El argumento del individualismo ético se complementa con el de la imparcialidad. Segun éste, se requiere de un metacriterio que permita resolver los eventuales conflictos interculturales. Si se quiere evitar el enfrentamiento entre culturas, es necesario asumir un "punto de vista moral" que, con base en el reconocimiento de la pluralidad cultural, garantice la mutua tolerancia. Ésta es la perspectiva kantiana del liberalismo.

Ahora bien, la exigencia del pluralismo y de la imparcialidad no significa aceptar una perspectiva distante y austera ajena a un compromiso responsable con la vida política y social de la comunidad. Exige, más bien, un

21 Fernando Salmerón, "Ética y diversidad cultural", en Enciclopedia Iberoamericana de Filosofía, vol. 12, Cuestiones morales, Edición de Osvaldo Guariglia, Instituto de Filosofía del csic, Trotta, Madrid, 1996, p. 79.

22 Walter Beller Taboada, et al., op. cit., p. 106. 
consenso con respecto a los valores primarios que son necesarios satisfacer para el logro de una vida humana digna. Como sostiene John Kekes:

los pluralistas apelan a la distinción entre convenciones profundas y variables (deep and variable conventions). Las convenciones profundas protegen los requerimientos mínimos para toda vida buena, como quiera que sean concebidas. Las convenciones variables protegen también los requerimientos de la vida buena, pero estos requerimientos varían con las tradiciones y las concepciones sobre la vida buena. La pretensión de los pluralistas es que los valores protegidos por las convenciones profundas tengan un contexto de justificación independiente, mientras que los valores protegidos por las convenciones variables puedan ser legítimamente apreciados en algunos contextos pero no en otros. ${ }^{23}$

Los bienes primarios o las necesidades básicas así como los derechos humanos requieren de "convenciones profundas" a diferencia de las necesidades o deseos secundarios que requieren de "convenciones variables". Los primeros no están sujetos a negociación; los segundos, sí. Un pluralismo así entendido excluye el desacuerdo y el conflicto entre los individuos y los grupos: se parte de un consenso profundo con respecto a los bienes básicos pero, al mismo tiempo, se deja un amplio margen para el desacuerdo, el diálogo y la negociación con respecto a los valores que se sujetan a la contingencia de las diversas tradiciones culturales. Pienso que esta distinción es un punto de partida fundamental para comenzar a debatir sobre el problema del multiculturalismo. Poco se avanza en esta polémica si, sobre la base de un pluralismo mal entendido, se piensa que todas las culturas tienen igual valor y todas merecen igual respeto. Esta premisa es falsa. Las culturas que organizan su modo de vida a partir de una reiterada violación de los derechos individuales no tienen el mismo valor que aquéllas en las cuales su organización política y vida cultural no permiten tales violaciones o abusos de autoridad.

Es verdad, como sostiene Walzer, que el debate serio entre los filósofos no tiene que ver con el reconocimiento o no de los derechos. Todos parecen partir de la premisa de su existencia. ${ }^{24}$ Pero si bien esto es cierto está muy lejos de ser una demanda minimalista (minimalist claim) ${ }^{25}$ como parece desprenderse de la propuesta del autor. Muy por el contrario, el reconocimiento de los derechos humanos básicos es un primer paso para justificar las intervenciones humanitarias, según lo reconoce el propio Walzer, cuando afirma que: "los actos y prácticas que 'producen shock en la conciencia

23 John Kekes, The Morality of Pluralism, Princeton University Press, 1993, p. 31.

24 Véase Michael Walzer, On Toleration, Yale University Press, New Haven-Londres, 1997, pp. 5-6.

25 Ibid., p. 2. 
de la humanidad' son, en principio, intolerables", ${ }^{26}$ por ejemplo, la "crueldad, opresión, misoginia, racismo, esclavitud, o tortura". Si estas acciones son censurables lo son en la medida que atentan no contra los valores de la comunidad sino contra la autonomía y dignidad de los individuos que la integran. Por ello resulta incoherente en Walzer pronunciarse por una suerte de tolerancia que, carente de límites, puede asumir las formas de resignación, indiferencia, estoicismo, curiosidad o entusiasmo, ${ }^{27}$ según las culturas. Más bien, ante la violación de los derechos humanos básicos no cabe la resignación o la indiferencia, ni la tolerancia, sino una actitud de franca intolerancia. Esto supone asumir diferencias cualitativas entre las culturas.

Así pues, si aceptamos la distinción entre "consensos profundos" y "consensos variables", y asumimos que el respeto a los derechos humanos individuales es la mejor opción para juzgar la legitimidad de los derechos culturales y garantizar la imparcialidad, debemos aceptar que el ámbito de la tolerancia queda acotado precisamente por el respeto a tales derechos. Su ámbito quedaría reducido, entonces, al de las convenciones derivadas: a las necesidades o deseos secundarios.

Si tolerante es aquel que tiene el poder de tratar de suprimir o prevenir (o, al menos, de oponerse u obstaculizar) lo que resulta lesivo para sus convicciones pero se abstiene de hacerlo, es decir, no prohíbe el acto lesivo, la evaluación de no intervenir tiene sentido sólo si está tácitamente permitido en el sistema de reglas de la sociedad en la que se mueve el individuo. Esto quiere decir que ante una prohibición, un mandato o una permisión expresa desde el punto de vista jurídico, sustentada en las garantías individuales, no cabe la tolerancia. ${ }^{28}$ No tiene sentido siquiera plantearse la posibilidad de ser tolerante ante grupos minoritarios que atentan contra el derecho a la vida, por ejemplo, de los brujos tepehuanes o a la integridad física de la niña huichola. La violación de sus derechos exige no una abstención sino una intervención firme dentro de los cauces legales establecidos en el marco de una democracia constitucional.

Llego entonces a una conclusión obvia pero no por obvia intrascendente: mientras más fortalecida se halle una sociedad en la vigencia de los derechos y, entre éstos, con supremacía de los derechos individuales sobre los culturales, menos necesaria resultará la tolerancia. Ésta se moverá en el ámbito de lo tácitamente permitido que tiene que ver nada más, pero nada menos, con la moral autorreferente, o bien con la moral intersubje-

26 Ibid., p. 21.

27 Ibid., p. 12.

28 Véase Annette Schmitt, "Las circunstancias de la tolerancia", Doxa, no. 11, Universidad de Alicante, España, 1992, pp. 80-81. 
tiva, por ejemplo, filial conyugal o fraternal, siempre que no se incurra en daños a terceros por acción o por omisión. En términos de culturas, un multiculturalismo fuerte que argumente en contra del individualismo ético es inaceptable, y un multiculturalismo débil, coincido con Garzón Valdés, termina por reducir las peculiaridades éticamente respetables o, en su caso, tolerables, a tres ámbitos fundamentales: la lengua, el arte y las necesidades o deseos secundarios de las personas. ${ }^{29}$

Regreso finalmente a los tres casos citados al principio. Si debo escoger entre el interés de la niña huichola a no ser dañada en su integridad física, de los brujos tepehuanes a no ser quemados con leña verde y la infracción del principio de igualdad en la aplicación de la justicia penal para el homicida oaxaqueño, o bien, la alternativa de padecer la violación o perder la vida en aras del valor intrínseco de las culturas a las que pertenecen estos individuos, no me cabe duda alguna, deben prevalecer los derechos liberales sobre los culturales. En estas situaciones y en otras semejantes, el reconocimiento de derechos vuelve innecesaria la tolerancia.

29 Ernesto Garzón Valdés, "Derechos humanos y minorías", texto leído en el Seminario Eduardo García Máynez sobre Teoría y Filosofía del Derecho, rTAM-ULA-Escuela Libre de Derecho, México, 25 de septiembre de 1993. (Mimeografiado.) 